\title{
“Obrigada por ter apresentado a História Oral": propostas desenvolvidas e analisadas em um curso de Licenciatura em Matemática
}

\section{"Thank you for introducing me to Oral History": proposals developed and analyzed in a Mathematics Degree Course}

\author{
Mirian Maria Andrade \\ Línlya Sachs ${ }^{* *}$
}

\begin{abstract}
Resumo
Este texto tem por objetivo apresentar e compartilhar alguns apontamentos analíticos a partir da introdução de práticas de História Oral em espaços formais de formação inicial de professores, especificamente, num curso de Licenciatura em Matemática: na aula de História da Matemática; na aula de Metodologia e Prática de Ensino de Matemática na Educação Básica 2; e no Programa Institucional de Bolsas de Iniciação à Docência - PIBID. Nessas instâncias, três propostas de mobilização da História Oral foram apresentadas, desenvolvidas pelos alunos e analisadas a partir dos registros produzidos por esses licenciandos sobre suas impressões e compreensões do desenvolvimento dessas atividades. Desenvolver essas atividades e analisar esses registros nos permitiu perceber algumas potencialidades da História Oral em sala de aula e o modo como essas atividades e suas implicações tocaram esses alunos em diversos aspectos, inclusive, para além do propósito inicial de formação de professores.
\end{abstract}

Palavras-chave: Formação Inicial de Professores. Narrativas. Sala de aula. PIBID. História Oral.

\begin{abstract}
This paper aims to present and share some analytical notes from an introduction in Oral History practices in formal spaces of initial teacher training, specifically, in a Mathematics Degree Course: in a "History of Mathematics" class; in a "Methodology and Practice of Teaching Mathematics in Basic Education 2" class; and in the Institutional Program of Initiatives for Teaching - PIBID. In these instances, three proposals for mobilization of Oral History were presented, developed by the students and analyzed from the records produced by these graduates on their impressions and understandings of these activities' development. Developing these activities and analyzing these records allowed us to understand some of the Oral History's potentialities in the classroom and the way in which these activities and their implications have touched these students in several aspects, including the initial purpose of teacher training.
\end{abstract}

Keywords: Initial Teacher Training. Narratives. Classroom. PIBID. Oral History.

\footnotetext{
* Doutora em Educação Matemática pela Universidade Estadual Paulista "Júlio de Mesquita Filho" (Unesp). Professora da Universidade Tecnológica Federal do Paraná (UTFPR), Cornélio Procópio/PR, Brasil. Endereço para correspondência: Avenida Alberto Carazzai, 1640, Cornélio Procópio/PR, CEP 86300-000. Endereço eletrônico: andrade.mirian@gmail.com.

*** Doutora em Educação Matemática pela Universidade Estadual Paulista "Júlio de Mesquita Filho" (Unesp). Professora da Universidade Tecnológica Federal do Paraná (UTFPR), Cornélio Procópio/PR, Brasil. Endereço para correspondência: Avenida Alberto Carazzai, 1640, Cornélio Procópio/PR, CEP 86300-000. Endereço eletrônico: linlyasachs@yahoo.com.br.
} 


\section{Introdução}

Neste texto, temos a intenção de tratar sobre uma experiência de introdução da História Oral na prática educacional. Para tanto, discorreremos sobre como se deu o uso de História Oral em diferentes instâncias educacionais do curso de Licenciatura em Matemática da Universidade Tecnológica Federal do Paraná, câmpus Cornélio Procópio. Por instâncias educacionais entendemos os espaços formais de formação de professores de Matemática, de acordo com Silva (2016, p. 175): "processos institucionalizados com vistas à formação de professores de Matemática, que habilitam pessoas para o exercício do magistério nessa área, como por exemplo, licenciaturas em Matemática [...]".

Foram realizadas, durante o ano letivo de 2016 e no início do ano letivo de 2017, três atividades com alunos deste curso em que a História Oral foi mobilizada. Ao mobilizarmos a História Oral, nesses espaços, no curso de Licenciatura, entendemos que a tomamos sob dois modos, como metodologia para constituir narrativas e, também, como uma abordagem de ensino. Isso nos permitiu, como professoras e pesquisadoras, pensar nas contribuições que a História Oral pode trazer para esses espaços de formação inicial. Em todas as atividades propostas, foi preciso disparar narrativas e, nesses momentos, a História Oral foi mobilizada pelos alunos, para este fim, como uma metodologia para constituir narrativas. No entanto, ao dispararmos as propostas, nas disciplinas, tivemos o objetivo de ser esta uma abordagem de ensino ou, para nós, uma nova possibilidade de abordagem de ensino. De todo modo, não é nosso objetivo, neste momento, aprofundar as discussões sobre essas questões que envolvem a mobilização da História Oral.

É importante destacar que, entendemos narrativa, de acordo com Garnica (2012, p. 340), como sendo:

[...] a experiência estruturada como relato, como um "contar", como forma de construir sentidos (um sentido para o si-próprio - aquele que narra, narra-se ao mesmo tempo em que narra algo - e um sentido para o que é narrado) a partir de ações cravadas no tempo, usando a descrição sobre algo, alguém ou sobre si próprio (biografia).

Ainda, para Garnica (2012, p. 340), “ouvir o outro - princípio fundamental àqueles que trabalham com narrativas - implica a tentativa de compreender experiências e criar estratégias de ação, por exemplo, para futuros professores. Daí a importância de levar aos cursos de Licenciatura o trabalho com narrativas”. Para Tizzo, Flugge e Silva (2015, p. 890), "a narrativa pode ser compreendida como uma reconstrução de experiências". Trata-se, de acordo com esses autores, de um processo de reflexão em que se atribui significado ao que foi 
vivido e experienciado. Por experiência entendemos o que nos afirma Larrosa (2002), ao apontar que experiência não está relacionada com o tempo de trabalho, "a experiência é o que nos passa, o que nos acontece, o que nos toca. Não o que se passa, não o que acontece, ou o que toca" (p. 21), é o que nos toca e, quando nos toca, nos transforma de algum modo. Ainda, assim como observa Larrosa (2014), não temos aqui uma pretensão de autoridade com a nossa experiência, tampouco a aproximamos da prática, considerando-nos sujeito ativos - mas, sim, passionais - ou do experimento, do empírico, daquilo que pode ser produzido cientificamente ou tecnicamente.

Nossa inspiração e fundamento teórico-metodológico está, sobretudo, em Santhiago e Magalhães (2015), quando tratam, especificamente, da História Oral na sala de aula e das potencialidades que adotar essa prática pode trazer para os momentos de ensino e de aprendizagem dos alunos, seja na aula de Matemática ou de qualquer outra disciplina. Tizzo e Silva (2016, p. 32) também nos ajudam a fundamentar nossas propostas e acreditamos, como eles, que "são diversas as contribuições que uma atividade desta natureza pode oferecer ao desenvolvimento intelectual dos alunos”. Esses autores se inspiram, ainda, na literatura para afirmar que "propor um trabalho com HO [História Oral] em sala de aula é um modo de requerer e promover, entre os alunos, capacidades e atitudes, tais como habilidades de indagação e análise, características essenciais para o desenvolvimento de um pensamento crítico" (p. 32, colchetes nossos), além de apontar que o processo de produção de narrativas em cursos de formação de professores "gera reflexões, conflitos, aprendizagens, mobilização, além de permitir um processo de transformação do saber docente possibilitado pelo intercâmbio de experiências entre os profissionais envolvidos em uma atividade com essas características" (p. 32).

A História Oral foi trabalhada como possibilidade de intervenção e a proposta para este texto é lançar um olhar analítico para o que alguns dos alunos participantes dessas intervenções relataram sobre ela. Posteriormente à realização das atividades, alguns alunos participantes delas foram convidados para contar sobre o que vivenciaram com a realização das respectivas intervenções. A intenção era ouvir deles sobre as dificuldades e as facilidades quanto à realização da proposta e, mais que isso, ouvir deles as potencialidades da História Oral nesses espaços específicos de formação e tentar perceber se (e como isso), de algum modo, algo lhes passou nesses lugares de experiência. De acordo com Larrosa (2011), podemos afirmar que essas atividades propostas, essas ações ou práticas, podem ser consideradas lugares de experiência, pois é na ação ou na prática que, às vezes, algo me passa. No entanto, a própria ação não pode ser considerada experiência, já que experiência não é 
intencional.

A experiência é o que me passa. Não o que faço, mas o que me passa. A experiência não se faz, mas se padece. A experiência, portanto, não é intencional, não depende de minhas ações, de minha vontade, não depende do que eu queira fazer (ou padecer) uma experiência. A experiência não está do lado da ação, ou da prática, ou da técnica, mas do lado da paixão. Por isso a experiência é atenção, escuta, abertura, disponibilidade, sensibilidade, vulnerabilidade, ex/posição (LARROSA, 2011, p. 22).

Os alunos foram convidados a registrar, em forma de texto, as suas respectivas impressões.

\section{Tentativas de História Oral em espaços de formação: as atividades desenvolvidas no curso de Licenciatura em Matemática}

Nesta seção, relataremos as três atividades desenvolvidas com os alunos do curso de Licenciatura em Matemática em que a História Oral foi mobilizada, como abordagem de ensino ou de pesquisa. Essas atividades aconteceram em espaços distintos existentes neste curso: a) na disciplina de Metodologia e Prática de Ensino de Matemática para a Educação Básica 2 (obrigatória); b) na disciplina de História da Matemática (obrigatória); e c) no Programa Institucional de Bolsas de Iniciação à Docência - PIBID. Ressaltamos que essas ações se mostraram como possibilidades, sempre quando buscávamos trazer para esses espaços outros modos de intervenção. No entanto, inspirados em Tizzo, Flugge e Silva (2015), é que ressaltamos que essas atividades não se configuraram, para nós, como experimentações; foram estratégias de ensino e de pesquisa, cuidadosamente pensadas, para cada um desses contextos disciplinares e de iniciação à docência. Nosso apoio na literatura, além da participação e da proximidade de grupos de pesquisas que mobilizam a História Oral como metodologia de pesquisa, nos permitiu ter condições para elaborar e realizar essas atividades com os estudantes desse curso de Licenciatura, futuros professores de Matemática e refletir sobre elas.

\section{Atividade 1: ouvir e escutar professores e futuros professores de Matemática}

$\mathrm{O}$ ato de ouvir exige humildade de quem ouve. E a humildade está nisso: saber, não com a cabeça, mas com o coração, que é possível que o outro veja mundos que nós não vemos (ALVES, 2008, p. 32).

[...] ouvir teria o sentido de capturar um som pelo ouvido, enquanto escutar teria o sentido de busca de sentido e entendimento ao que se ouve, o que implica assumir uma postura de estudo e de produção de significados. [...] o escutar do pesquisador não consiste apenas em ouvir o que o professor diz, mas escutar o que está além, o que está nas entrelinhas do discurso do professor - o que é singular a cada um ou a 
"verdade" de cada um. Daí a importância de ampliar as escutas, de desenvolver pesquisas que acionem ou mobilizem vários modos de escuta, isto é, diferentes modos de significação e compreensão das experiências narradas pelos professores (FIORENTINI, 2012, p. 16, grifos do autor).

A atividade, que aqui chamamos de atividade 1 , foi realizada na disciplina de Metodologia e Prática de Ensino de Matemática para a Educação Básica 2, no segundo semestre letivo de 2016, prevista no Projeto Político-Pedagógico do curso de Licenciatura em Matemática, obrigatória e recomendada aos alunos matriculados no quinto período do curso ${ }^{1}$. Trata-se de uma disciplina cuja carga horária é de 30 horas, que se cumprem ao longo do semestre, com encontros presenciais de 2 horas-aula semanais. A metodologia utilizada para a realização dessa atividade teve aproximações com a História Oral, tendo como principais interlocutores Santhiago e Magalhães (2015), quando tratam do trabalho com História Oral na sala de aula. Os alunos da disciplina fizeram a leitura de um texto sobre essa metodologia, para entender o que estava sendo proposto pela professora, mas não aprofundaram as discussões porque não era esse o objetivo naquele momento.

Nessa atividade, a História Oral foi pensada como abordagem de ensino que, de acordo com Santhiago e Magalhães (2015, p. 10),

[...] diversifica caminhos em direção ao conhecimento, porque valoriza a autonomia do aluno e proporciona um aprendizado ativo, participativo e colaborativo. Ela permite que o aluno não seja apenas um receptáculo de dados - e que passe para a condição de sujeito ativo, criativo, do conhecimento.

O tema gerador da pesquisa, que compunha essa atividade, era o estágio supervisionado no curso de Licenciatura em Matemática. O trabalho foi realizado em grupos. Cada grupo escolheu três sujeitos (colaboradores) para entrevistar: um professor do Ensino Superior que estivesse ministrando ou tivesse ministrado alguma disciplina de estágio supervisionado; um professor da Educação Básica que já tivesse recebido, em suas aulas de Matemática, alunos estagiários do curso de Licenciatura em Matemática; e um aluno do curso de Licenciatura em Matemática que estivesse cursando uma disciplina de estágio

\footnotetext{
${ }^{1}$ Com a reestruturação da grade curricular deste curso de Licenciatura em Matemática, em vigor a partir do segundo semestre letivo de 2017, os conteúdos que antes eram abordados nesta disciplina e nas disciplinas de Metodologia e Prática de Ensino de Matemática para a Educação Básica 1 e Metodologia do Ensino de Matemática, ambas obrigatórias e com a mesma carga horária (2 horas-aulas semanais) foram repensados e deuse origem a uma única nova disciplina: Metodologia do Ensino de Matemática, com carga horária de 60 horas ou 4 aulas semanais. Essas alterações aconteceram em virtude da reestruturação do currículo com vistas a atender a Resolução $\mathrm{n}^{\circ}$ 02, de $1^{\circ}$ de julho de 2015, do Ministério da Educação - Conselho Nacional de Educação Conselho Pleno, que "define as Diretrizes Curriculares Nacionais para a formação inicial em nível superior (cursos de licenciatura, cursos de formação pedagógica para graduados e cursos de segunda licenciatura) e para a formação continuada".
} 
supervisionado $^{2}$. Como havia um tema disparador da entrevista, podemos afirmar que os alunos desenvolveram o que Santhiago e Magalhães (2015) chamam de entrevista temática.

Para a elaboração da proposta dessa atividade, nos pautamos em Tizzo e Silva (2016, p. 30, colchetes nossos) quando afirmam que "pesquisas 'não historiográficas' também têm utilizado a HO [História Oral] como metodologia de pesquisa, já que esta atende às demandas de pesquisas preocupadas, em especial, com os significados atribuídos pelos sujeitos às suas vivências".

Os grupos elaboraram, colaborativamente, os roteiros das entrevistas, escolheram os colaboradores e agendaram as entrevistas com envio prévio do roteiro. De posse dos áudios, os estudantes transcreveram e textualizaram as entrevistas. "A transcrição é o nome que damos à transformação do registro sonoro em texto "fiel'" (VIANNA, 2014, p. 75). E a textualização “transforma a entrevista de 'língua falada' em um texto de 'língua escrita', um texto que terá a estrutura, o formato e o grau de elaboração conceitual e técnico que lhe possa ser dado pelo autor" (VIANNA, 2014, p. 76). Os colaboradores assinaram as cartas de cessão para que os alunos pudessem usar o material gerado a partir das textualizações das entrevistas. Seguiram, portanto, os procedimentos indicados quando se devolve um trabalho em que se mobiliza a História Oral.

Em seguida, como análise desse material, os alunos procederam com a escrita de uma narrativa sobre o estágio supervisionado no curso de Licenciatura em Matemática, a partir das textualizações dos três sujeitos entrevistados. "As narrativas orais, registradas em momentos de entrevista, são as matérias-primas por excelência de todo um processo hermenêutico que, entretanto, não dispensa narrativas outras, como por exemplo, as escritas" (GARNICA, 2014, p. 58).

Para proceder com a análise, os grupos optaram por dispará-las individualmente. Cada textualização gerou o que foi chamado de "narrativa da entrevista de [fulano]". Após esse exercício analítico, os grupos se propuseram a tecer uma análise geral, olhando para as possíveis convergências e divergências dessas vozes sobre a temática “estágio supervisionado

\footnotetext{
${ }^{2}$ Este curso de Licenciatura em Matemática possuía, até o primeiro semestre de 2017, em sua grade curricular, quatro disciplinas obrigatórias de estágio supervisionado, denominadas de Estágio Supervisionado A (estágio para observação), Estágio Supervisionado B (desenvolvimento de observação e oficinas), Estágio Supervisionado C (observação e regência no Ensino Fundamental) e Estágio Supervisionado D (observação e regência no Ensino Médio). Essas disciplinas eram obrigatórias a partir do quinto período do curso. Para a realização da entrevista, os alunos deveriam escolher um aluno que estivesse matriculado na disciplina de Estágio Supervisionado C ou D e que, portanto, já teria uma vivência do estágio para comunicar. A partir do segundo semestre letivo de 2017, essas disciplinas sofreram alterações, passando o estágio supervisionado a não ser mais realizado em forma de disciplinas, neste curso.
} 
no curso de Licenciatura em Matemática”. Essa atividade ocorreu na segunda metade do semestre letivo, paralelamente às demais atividades da disciplina. Os alunos realizaram a socialização do trabalho de cada grupo e entregaram um relatório escrito contendo todo o material produzido e analisado por eles, bem como as autorizações. Nesse caso, podemos afirmar que o conhecimento dos alunos sobre a temática estudada foi impulsionado por perguntas e não por respostas. Um dos grupos participantes dessa atividade submeteu os resultados desta atividade, como trabalho de comunicação científica em um evento científico de Educação Matemática. O trabalho foi aprovado e apresentado pelos alunos, naquele evento.

\section{Atividade 2: memórias convidadas protagonizam a aula}

A atividade 2 também foi realizada em uma disciplina obrigatória, cuja carga horária é de 60 horas, da grade curricular dos alunos matriculados nesse curso: História da Matemática. $\mathrm{Na}$ ementa dessa disciplina, apresentada no Projeto Político-Pedagógico do curso de Licenciatura em Matemática, está previsto que seja abordado, entre outros itens, o trabalho com "História da Educação Matemática"3. Como professores, nos perguntamos: como trabalhar História da Educação Matemática (algo amplo) em tão curto tempo? Por outro lado, consideramos ser essa uma boa oportunidade para trabalhar com o tema na formação inicial de professores de Matemática. Pensando em possibilidades para desenvolver esse tema, propusemos o trabalho com a História Oral na sala de aula, fundamentados teóricometodologicamente na História Oral em Educação Matemática, para a realização de uma das atividades que envolvia esse tema. Na Educação Matemática, trabalhos que assumem a História Oral como metodologia de pesquisa têm usado essa abordagem mais frequentemente em estudos acerca da História da Educação Matemática que intencionam estudar a história da formação de professores, das instituições escolares, da matemática escolar e legislações.

Os alunos, após um estudo teórico sobre a História da Educação Matemática, por meio de leituras e discussões em sala de aula, foram convidados a conversar com seus pais, avós ou outras pessoas com quem tivessem fácil contato para a realização da atividade sobre o ensino de Matemática na época em que essas pessoas tinham estudado na Educação Básica. A proposta era, portanto, a realização de uma entrevista com essas pessoas. Para essa entrevista, os alunos prepararam, com a ajuda e orientação da professora, um roteiro de entrevista que tocava em questões de ensino e de aprendizagem de Matemática e em questões relacionadas

\footnotetext{
${ }^{3}$ Essa disciplina não sofreu alterações de carga horária e de conteúdo, com a reestruturação do curso.
} 
ao ensino de modo geral. Agendaram, então, suas respectivas entrevistas. Nessa atividade, cuidou-se do registro das memórias dos colaboradores, permitindo que eles adentrassem, com as suas histórias, à nossa sala de aula, disparando momentos interessantes de pesquisa e conhecimento, memórias convidadas que protagonizaram as aulas. "Ao produzir fontes de informação e consolidar conhecimento, o interesse do estudante pelo objeto de aprendizagem tende a aumentar" (SANTHIAGO, MAGALHÃES, 2015, p. 10). Silva (2016, p. 174, colchetes nossos) destaca que a fonte oral "[...] mostra como os sujeitos o [o fenômeno] perceberam, digeriram, significaram; por isso mais do que informar sobre acontecimentos, a fonte oral trata dos significados que eles tiveram/têm para as pessoas que os vivenciaram".

As entrevistas foram gravadas e os alunos produziram um texto narrativo a partir das histórias narradas, transcreveram os áudios e textualizaram. Esses textos foram devolvidos para os entrevistados (colaboradores), que indicaram alterações ou aprovaram a narrativa sem a necessidade de mexer no texto. Naquele momento, nosso interesse não era divulgar esse material e, por isso, os colaboradores não assinaram cartas de cessão, mas, na maioria, autorizaram e até pediram que fossem identificados no momento da socialização e da entrega do material como atividade da disciplina.

De posse da narrativa, os alunos escolheram alguns pontos destacados pelos entrevistados para realizar uma pesquisa. Muitos alunos se motivaram a pesquisar sobre os castigos, sobre o uso, a obrigatoriedade e a função do uniforme, sobre as salas de aula multisseriadas, sobre a estrutura das escolas (principalmente as escolas rurais), questões de gênero que apareceram, sobretudo, na fala das entrevistadas mulheres (e que foi apontado, por elas, como sendo um dificultador para que estudassem), sobre as cartilhas, sobre as funções exercidas pelas professoras dentro das escolas (que iam além da tarefa de ensinar, tendo muitas vezes obrigações como merendeiras, faxineiras e outras).

Os pontos escolhidos por cada aluno, para a pesquisa, refletiram o que mais chamou a atenção deles no momento da entrevista. E eles puderam perceber que muitas coisas mudam com o tempo e outras permanecem, mas mudam de função com o tempo e, ainda, puderam perceber o movimento da história e como a História da Educação Matemática nos permite entender algumas permanências e algumas alterações. Para Santhiago e Magalhães (2015, p. 14), “ouvindo histórias dos mais velhos, os alunos percebem mais facilmente que eles próprios têm um passado e que terão um futuro, compreendendo que suas ações têm repercussão no tempo". Assim, “os jovens passam a valorizar as experiências dos mais idosos, reconhecendo-as como conselhos úteis", além de "[...] se reconhecer[em] como protagonistas e produtores de histórias, reforçando sua consciência histórica". 
Todos os textos foram socializados na sala de aula em forma de roda de conversa. Durante a socialização, foram feitos alguns relatos pelos alunos, muitos deles envolvendo descobertas sobre o tempo escolar de pessoas próximas a eles e que eles não conheciam, como, por exemplo, um aluno descobriu que o avô usou caneta de pena na infância. Outro relato considerou a emoção do colaborador ao ler a narrativa escrita pelo aluno.

Com a socialização do texto e da pesquisa que cada aluno realizou sobre os temas destacados nas narrativas, foi possível compreender um pouco mais sobre as escolas, sobre o ensino nessas escolas, sobretudo o ensino de Matemática e a organização dessas instituições em diferentes épocas. O momento da socialização foi bastante relevante para os alunos, proporcionando discussões que contribuíram com o objetivo de se trabalhar História da Educação Matemática, disparadas por sujeitos alheios a essa sala de aula. O tempo estimado para a realização deste momento de socialização precisou ser repensado e aumentado, grande foi o envolvimento dos alunos ao socializarem sua própria entrevista (ou seja, a entrevista que tinham realizado e disparado as demais atividades), ao escutar a socialização dos colegas e nas interessantes discussões disparadas naquele momento.

\title{
Atividade 3: como o professor de Matemática se torna o professor de Matemática que é?
}

\begin{abstract}
Por que escutar professores e professoras de Matemática? Por que escutar professores de Matemática que vivem e constroem suas experiências docentes em um espaço e em um tempo determinados - o espaço e o tempo das salas de aula do Ensino Fundamental e Médio? Uma primeira resposta a essa pergunta seria porque somos, também, professores de Matemática (PAULA; AUAREK, 2012, p. 33).
\end{abstract}

[...] não há uma trajetória na docência, mas sim trajetória na vida, e nesta, nessa trajetória de vida, há a docência (PAULA; AUAREK, 2012, p. 37).

Inspiradas em Rolkouski (2008) é que demos início às nossas atividades de orientação no PIBID. O PIBID, no curso de Licenciatura em Matemática, neste câmpus, estrutura-se do seguinte modo: os coordenadores do projeto convidam alguns professores do curso para orientar duplas de bolsistas em atividades teóricas. Desse modo, apesar de não sermos coordenadoras desse projeto, contribuímos com ele por meio da orientação de alguns bolsistas. A atividade que mobilizou a História Oral ocorreu e ocorre nesse espaço de orientação e, portanto, não alcança todos os bolsistas do projeto, apenas aqueles que a nós são encaminhados para essas orientações. Durante o ano letivo de 2016, com a orientação de duas duplas de alunos, iniciamos nossos estudos e aproximações metodológicas com a História Oral.

A proposta tinha como principal objetivo olhar para o professor supervisor dos alunos na escola básica. Iniciamos pela leitura do texto "História de vida de professores de 
Matemática", de Rolkouski (2008). Na sequência, os alunos produziram um texto e o socializaram no grupo, relatando suas histórias de vida, lançando uma reflexão sobre o caminho que levou cada um deles para o curso de Licenciatura em Matemática. O que era para ser apenas um exercício sobre escritas de histórias de vida, tomou outras proporções. Os caminhos e os (des)caminhos tomados por esses estudantes para chegarem ao curso de Licenciatura e permanecerem nele também geraram trabalhos que foram submetidos, aprovados e apresentados em eventos científicos próprios da Educação Matemática e do PIBID. Outras leituras sobre a metodologia de História Oral foram realizadas e discutidas no grupo. Os alunos estudaram alguns fragmentos de entrevista e textos que foram escritos a partir desses fragmentos, expostos no livro "Viver e contar: experiências e práticas de professores de matemática", de Teixeira et al. (2012). Nesse livro, são apresentadas onze maneiras (textos) de escutar as narrativas de professores de Matemática.

Após esse contato com a literatura e o desenvolvimento de algumas atividades e leituras em grupo, tínhamos, então, condições de ouvir e escutar esses professores de Matemática, supervisores desses bolsistas. Lançamos a pergunta: como esses professores de Matemática, supervisores do PIBID, se tornaram os professores de Matemática que são? “A escuta de histórias de vida proporciona ao aluno compartilhar visões, ideias e opiniões; ficar sensível às diferenças entre as pessoas, na medida em que exige o contato com situações de vida e opiniões diferentes. E tudo isso é feito na esfera do concreto" (SANTHIAGO; MAGALHÃES, 2015, p. 11).

Orientados, os alunos elaboraram um roteiro de entrevista. De posse do roteiro, eles agendaram a entrevista com os professores, que receberam, individualmente, uma cartaconvite relatando as intenções do trabalho. Foram entrevistados três professores. Com o aceite dos professores, os bolsistas criaram fichas-temas que foram elaboradas a partir das questões que compunham o roteiro para as entrevistas. As fichas-temas, confeccionadas em papel cartolina, continham, cada uma, uma palavra-chave referente a uma pergunta do roteiro de entrevista e foram elaboradas para disparar a entrevista, sem a necessidade de ler as perguntas. Essas fichas foram colocadas frente ao colaborador no momento da entrevista. $\mathrm{O}$ uso das fichas-temas, inspiradas na pesquisa desenvolvida por Rolkouski (2006), permitiu o não desvio do assunto no decorrer da entrevista e uma menor interferência do entrevistador durante a fala do colaborador. Essa estratégia foi comunicada aos professores entrevistados antes que se iniciasse cada entrevista. Eles compreenderam a proposta e fizeram uso dessas fichas-temas para direcionar suas falas.

Seguindo os procedimentos de um trabalho de História Oral, após a realização das 
entrevistas, os alunos procederam com a degravação ou transcrição dos áudios e com a textualização. Os professores entrevistados receberam as textualizações, aprovaram e assinaram as cartas de cessão. Esse material, que busca olhar para os caminhos que esses professores trilharam e trilham, as suas trajetórias de vida em que há a docência e o PIBID, foi analisado pelos alunos ${ }^{4}$.

\section{Relatos convidam para registros: aspectos metodológicos}

Após a realização dessas três atividades, convidamos alguns alunos para escreverem sobre essas aproximações com a História Oral.

O convite foi realizado pessoalmente, em um primeiro momento, a alguns alunos que realizaram essas atividades. Escolhemos aqueles com quem ainda tínhamos contato - em outras disciplinas, por exemplo, ou que se mantinham no PIBID - e que nos relataram, em algum momento, sobre o entusiasmo ou o interesse em realizá-las. Esses relatos espontâneos, que nos chegavam constantemente, é que nos impulsionaram a escrever sobre eles, de modo formal. Essas pequenas confissões, sobre como tinha significado para esses alunos o trabalho com essa metodologia, nos fizeram repensar esses registros, que antes não tinham sido realizados desse modo.

Após o aceite desses alunos, elaboramos e enviamos, por e-mail, uma sugestão, contendo o que gostaríamos que eles escrevessem. Essa sugestão foi pensada a partir dos relatos informais que nos chegaram. As orientações para a produção desses relatos foram parecidas para as três atividades, modificando apenas os trechos que, abaixo, colocamos entre colchetes e precedidas por (1) para a atividade 1, (2) para a atividade 2 e (3) para a atividade 3.

\footnotetext{
${ }^{4}$ A discussão sobre essas histórias de vida, sobre o modo como essas narrativas nos permitiram compreender como esses professores de Matemática se tornam os professores de Matemática que são, é objeto central que pretendemos tratar em um outro texto, específico desta ação.
} 
Produza um texto narrativo sobre as suas impressões quanto ao uso da História Oral (procedimentos: elaboração do roteiro de entrevista, contato com os entrevistadoscolaboradores, confecção das fichas-temas, a entrevista, a transcrição e a textualização) para a realização das atividades [(1) na disciplina de Metodologia e Prática de Ensino de Matemática na Educação Básica 2/ (2) na disciplina de História da Matemática/ (3) no PIBID] [(1) que buscaram compreender o Estágio Supervisionado no curso de Licenciatura em Matemática/ (2) que buscavam envolver o estudo de História da Educação Matemática/ (3) que buscam envolver o professor supervisor com o objetivo de compreender como esse professor de Matemática se torna o professor de Matemática que é].

Tente destacar, neste texto, sobre as facilidades e as dificuldades deste processo, as suas potencialidades e as suas limitações. Tente sinalizar, também, a importância (ou não) dessa atividade para a sua formação como professor de Matemática. Busque destacar, ainda, os momentos que mais o tocaram neste movimento com os colaboradores até o encerramento da atividade.

Obtivemos respostas de três alunos que realizaram a atividade 1, dois que realizaram a atividade 2 e uma que realizou a atividade 3. Os textos por eles produzidos se diferem em diversos aspectos. Há aqueles que, em 15 linhas, responderam às sugestões colocadas e há os que usaram quatro páginas para contar sobre; há aqueles que abordaram questões mais técnicas, da elaboração do roteiro de entrevista e da transcrição dos áudios e há aqueles que trataram dos sentimentos envolvidos nas atividades realizadas, da alegria, do brilho nos olhos; há aqueles que escreveram mais sobre a importância das atividades para a sua formação inicial e dos professores que serão e há os que pouco escreveram sobre isso.

Além desses registros, os alunos bolsistas do PIBID possuem um grupo de discussão, nas redes sociais, sobre as atividades que são desenvolvidas nesse grupo. É um modo de comunicação e de registro, também. Autorizadas, por meio de documento escrito, por esses alunos, também buscamos compreensões deles, sobre esse processo, nos relatos e discussões que foram disparados nesse espaço e também foram considerados para a elaboração e escrita deste texto.

Optamos por não apresentar na íntegra essas narrativas por eles produzidas, mas por escrever um texto nosso sobre o que eles registraram, sobre os sentidos por nós atribuídos àquilo que eles relataram. Optamos, portanto, por narrar as experiências dos nossos alunos, a partir daquilo que os tocou e os passou. Destacaremos em itálico e entre aspas os trechos escritos pelos alunos, para diferenciar aquilo que nós narramos daquilo que eles narraram. Há 
algumas inserções nossas nesses trechos e, para identificá-las, escrevemos entre colchetes.

\section{4 "Que mesmo em face do maior encanto, dele se encante mais meu pensamento": uma narrativa...}

As expectativas tomaram conta de nós, professoras que propuseram as atividades com História Oral no curso de Licenciatura em Matemática. O que esperávamos com isso? Contribuir com a formação do professor - o que mais poderíamos querer? Em um contexto de tanta valorização, por parte dos professores e, consequentemente, dos alunos, da Matemática - qual Matemática? Aquela que será útil para o professor? Não, claro que não! -, a nossa proposta foi no caminho contrário.

Queríamos valorizar histórias de vidas (histórias de vidas que se encontram, de algum modo, com a docência), queríamos valorizar os modos de compreensão desses personagens sobre alguns aspectos de nosso interesse, em particular, e queríamos, ainda, que esses futuros professores também fizessem isso, queríamos que eles se lembrassem (ou soubessem) que a profissão do professor não é um trabalho exato, não lida apenas (se é que lida com isso tudo) com números, com proposições, com teoremas, com demonstrações, com cálculos, mas, essencialmente, com gente! Gente que tem vida, que tem história, que tem memória. Vidas de “pequenas grandes pessoas" ou de grandes pequenas pessoas ou, simplesmente, de pessoas pessoas que importam!

E o que a História Oral tem com isso? O "processo de ouvir" o que as pessoas têm a falar é "sentir como se estivesse junto com ele[s] vivenciando suas passagens, imaginando os cenários, [nos] situando no tempo e espaço que ele[s] narrava[m] ”. É viver a vida do outro, nem que seja por um único instante. É tentar entender quem ele é, como ele se torna quem é, é conhecer o que ele viveu, é perceber o que mudou. É "ver o brilho nos olhos de alguém que parecia ter voltado no tempo ao responder as questões que eram feitas". É ter "um olhar mais afetuoso sobre as atitudes do professor [...] na sala de aula”.

Por outro lado, nós, professoras, víamos esse processo de "humanização" nos contaminar. Com as histórias de suas vidas que os bolsistas do PIBID desenvolveram (na atividade 3), passávamos a olhar com mais humanidade para eles, conhecendo um pouco de seus anseios, suas tristezas, suas responsabilidades, seus desejos, seus problemas, suas vidas. E, também, os entrevistados - alguns conhecidos por nós, outros não - das três atividades

\footnotetext{
${ }^{5}$ Trecho do Soneto de Fidelidade, de Vinícius de Moraes.
} 
tornaram-se mais cheios de vida para nós, quando líamos as transcrições, as textualizações e conversávamos sobre elas e sobre "os instantes de comoção presentes no áudio [que] foram intransmissíveis ao texto e ficaram aqui na [...] memória” apenas.

E os outros alunos, aqueles que não escolhemos para escrever suas narrativas ou que não atenderam ao nosso convite? Será que tudo isso vale para eles também? Não sabemos. Pode ser que não e, acreditamos, certamente, teríamos outros relatos. Afinal, são outras vidas, outros olhares, seriam outras narrativas.

Mas nossas expectativas não paravam por aí. Queríamos mais. Queríamos que a História Oral contribuísse com a formação desses professores de forma mais específica também.

$\mathrm{Na}$ atividade 1, queríamos, também, que os alunos passassem por um processo de “reflexão e preparação”. "Reflexão, pois analisando as entrevistas [eles poderiam] perceber que uma regência pode interferir de forma positiva ou negativa em uma sala de aula e isso pode prejudicar o professor da turma, então é necessária essa reflexão se o que está sendo preparado na regência está contribuindo ou não para a turma. Preparação, pois [...] a partir das opiniões ouvidas no trabalho, [eles podem se] preparar melhor para [...] as regências".

Compreendemos que o estágio supervisionado é um momento muitíssimo importante na formação inicial do professor e que ele não deve acontecer de maneira técnica. A questão “para que serve o estágio?" - que nunca nos é feita, talvez por ser um dos raros momentos no curso em que a prática aparece explicitamente - deveria surgir como um disparador de reflexões durante sua realização. Os alunos que participaram dessa atividade estavam, alguns, cursando a primeira disciplina de estágio e outros se preparando para, em um semestre próximo, cursar. Pensando nisso, essa reflexão que a realização das entrevistas proporcionaria poderia ser importante "para a formação [desses professores], por conta de não ter cursado disciplinas de estágio” e, assim, auxiliar "para que se pudesse chegar melhor preparado nos periodos referentes ao estágio". Conhecer o que diferentes sujeitos, "ao ver as diversas opiniões, de um aluno de estágio, um professor que recebe estágio e um professor que orienta o estágio", têm a dizer sobre o estágio supervisionado foi a maneira que encontramos para que os alunos percebessem como esse é um tema complexo, que envolve muita gente e muitas opiniões, e que influencia diretamente na formação desses futuros professores.

$\mathrm{Na}$ atividade 2, esperávamos que eles "[conhecessem] a forma do ensino de matemática no passado e também [pudessem] verificar como foi a transformação das escolas ao longo do tempo". Muita coisa mudou. Que escola era aquela do tempo do entrevistado? Quais “as transformações ocorridas ao longo do tempo”? O que essas pessoas podem nos 
contar que os livros não contam? Sabemos que, "apesar de termos acesso a fatos e acontecimentos históricos da época por meio da disciplina, aquela era uma porção da realidade da época por meio dos fatos e as experiências vividas por uma pessoa que era carregada de emoções e nostalgia”. Também queríamos saber o que se manteve com o passar do tempo.

Acreditamos que a história pode nos escancarar a não naturalidade das coisas, como elas são construídas e como elas podem, também, ser destruídas. Afinal, "não tem como entender o presente sem conhecer o passado, pois o ensino da matemática tem toda uma história”. Ou diríamos, é nesse presente que construímos um passado, é o passado narrado pelos olhos do presente, um passado que não existe, senão pela construção da memória do presente. E essa elaboração nos permite entender as alterações e permanências no ensino de modo geral e no de Matemática, em particular.

$\mathrm{Na}$ atividade 3, que são duas, na verdade, queríamos muita coisa! Mas o nosso "muita coisa" ficou pequeno quando as "muitas coisas", de fato, aconteceram. A atividade autobiográfica, ou de “'autotranscriação' da minha caminhada até aqui, aqui mesmo onde nesse momento, sentada em um ônibus indo a caminho da universidade, da janela vejo as plantações de milho do Paraná e um céu nublado de maio”, que seria apenas uma preparação para a entrevista a ser realizada com os professores, tomou proporções maiores do que o esperado. Talvez, por não sabermos que os alunos fossem tão criativos e poéticos ou por não sabermos que a nossa proposta de mobilização da História Oral pudesse enriquecer o nosso trabalho e tocar os bolsistas do modo como tocou, tomando caminhos que não participavam das expectativas iniciais do trabalho.

Uma aluna, por exemplo, contou sua história de vida como se duas pessoas conversassem em um banco de espera e sobre ela falassem. Cidade pequena, todos se conhecem. Assim, o papo fica mais interessante! Outra aluna inundou poesia em sua vida - ou em sua história de vida - e narrou como sua trajetória de vida a trouxe para um curso de Licenciatura em Matemática. Ela usou "o Soneto de Fidelidade, do poeta Vinícius de Moraes", como base para sua trajetória. Como ela diz, "por ter esse soneto decorado na minha vida, decidi inseri-lo na minha história contada até chegar na licenciatura, porque ele fala de um amor, um amor que eu trago pela matemática”. E, em um congresso, essa aluna teve a oportunidade de apresentar sua história de vida, essa que foi desenvolvida no âmbito desta atividade 3: "No momento da minha apresentação, em que usei slides, fiz primeiramente uma explicação geral sobre a história oral e, por fim, separado pelas suas quadras e as terças apresentei o soneto e minha história. Conforme eu ia contando a minha 
história, eu lia o trecho do soneto no slide. Para me sentir mais confortável e tirar um ar de seriedade que, às vezes, uma apresentação em pé em frente ao slide traz, me sentei na cadeira e botei o meu papel ajudante sobre a mesa, e passou a ter um ar de bate-papo (confesso que isso foi bom para o meu nervosismo), e olhando nos olhos dos que estavam presentes comecei 'De tudo ao meu amor serei atento' seguido dos caminhos e versos que percorri até chegar ao curso de licenciatura. Conforme ia contando cheia de entonações, notei os olhos brilhantes das pessoas que estavam ali diante dessa atividade não tão comum, pelo menos para mim. Para finalizar a apresentação fiz da seguinte forma: utilizei os nomes e os cursos das pessoas que assistiram e que eu havia anotado durante as apresentações, e fui indagando cada uma como se eu a conhecesse, dando o ar de querer ouvir a história da pessoa e sem esperar a resposta, para que houvesse uma reflexão interior nela, questionando um a um com perguntas do tipo 'E a sua história?', 'A sua inspiração?', 'Suas batalhas?', 'O que te fez chegar até aqui?'. Ao fazer isso, conclui com um 'Obrigada', bateram palmas, e após, como ocorreram em todas as apresentações, houve comentários. Foi emocionante esse momento”.

Essa preparação para a entrevista com o professor supervisor do PIBID foi muito mais que uma preparação. Roubou a cena! E essa atividade, que tinha como objetivo "conhecer a trajetória de como [o professor supervisor do PIBID] se tornou o professor que é hoje", fez com que a aluna tivesse "um olhar mais afetuoso sobre as atitudes do professor" e, como ela disse, "foi inesperado lidar com o sentimento fluindo no olhar do entrevistado". Por que será? Por que não esperamos sentimentos nos olhares dos professores? Precisamos pensar sobre isso, precisamos falar sobre isso, precisamos lidar com isso. E agradecida, a bolsista ficou, em seu momento de despedida, após a conclusão do curso: "obrigada pelas orientações, [...] e por ter apresentado a História Oral na minha vida”. Acreditamos nessa experiência.

Dos discursos registrados no grupo de estudos "acredito que o que estamos fazendo no PIBID [...] está permitindo 'darmos voz àqueles que não têm voz' ${ }^{36}[. .$.$] e principalmente$ valorizar as histórias de pessoas 'comuns'”. E, outro registro, complementa afirmando que “isso evidencia o aspecto democrático da História Oral”. Um terceiro registro pode sintetizar parte do movimento proposto pela atividade: “Através do PIBID nós mantivemos contato direto com a cultura e a profissão de um professor; assim, além das histórias proporcionarem

\footnotetext{
${ }^{6}$ Nesta afirmação, a aluna usa, em seu registro, uma força de expressão. Acreditamos que todos têm voz, mas que poucos se tornam audíveis. E entendemos que, quando assim escreve, ela se refere a essa abertura para ouvir, esse desejo e essa preocupação em ouvir pessoas "comuns" que muito têm a nos contar, que muito podem nos contar o que outros registros não contam.
} 
complemento a este contato, [com] o material obtido pode ser desenvolvida uma textualização, o propósito de ser incrementada a pessoas comuns, fornece-lhes voz e a oportunidade de compartilhar suas convicções e vivências munida com seus sentimentos. Este processo explicita todas as (con)vivências do indivíduo, de forma a ser um manifesto social documentado, assumindo desta maneira um caráter de 'contra-história' justamente por se construir uma individual, podendo se contrapor ou não das grandes narrativas; relatos tratados na História-Oral nos conduzem fontes de informações que se tornam importantes ferramentas para a construção de uma sociedade mais amplamente democrática, indicando as influências de sua cultura e sociedade no decorrer de sua história biográfica”.

Um movimento que se assemelha ao que anuncia um título dado a uma das referências utilizadas quando da elaboração e fundamentação desta atividade: "viver e contar experiências e práticas de professores de Matemática”. A mobilização da História Oral, neste caso, permitiu, uma aproximação, digamos, diferente da usual, dos alunos bolsistas de seus supervisores e dos supervisores com os alunos bolsistas, abrindo possibilidades novas de ações e de pesquisa.

\section{Fechando o texto e abrindo novas possibilidades com a História Oral}

Ler esses registros, que já nos eram anunciados por meio de relatos informais, nos permite considerar que os objetivos que tínhamos com as propostas de atividades foram extrapolados. Nosso desejo, menos audacioso, intencionava trazer a História Oral para as nossas aulas, mas não sabíamos direito como. Santhiago e Magalhães (2015) nos deram palpites, sugestões, nos possibilitaram fundamentação teórica. Trouxemos a História Oral para as salas de aula e para o PIBID. Nisso, também, nos auxiliaram os trabalhos de Silva (2016) e Tizzo e Silva (2016).

É importante ressaltar, no entanto, que algumas limitações foram encontradas neste caminho: muitas dúvidas sobre o que podíamos realizar de acordo com o que sugere o trabalho com a História Oral; dúvidas relacionadas ao uso dos nomes verídicos dos nossos colaboradores em nossos textos; sobre como proceder com as textualizações; e outras. Além disso, nem todos os alunos participantes das atividades 1, 2 e 3 se mostraram envolvidos com a História Oral e interessados em mobilizá-la.

Contudo, entendemos que a História Oral possibilitou romper fronteiras criadas pelo próprio engessamento dos cursos de Licenciatura, permitindo-nos conhecer quem são os alunos, suas histórias de vida, suas memórias, suas expectativas, e mesmo para que eles 
pudessem conhecer outros - professores supervisores do PIBID - com suas histórias de vida, nos percursos de ser professor de Matemática, amigos ou familiares, com suas memórias sobre a escola e as aulas de Matemática em suas épocas, e professores formadores, professores da Educação Básica e licenciandos, com seus olhares para o estágio supervisionado. A estrutura do curso, com a divisão por componentes curriculares e por períodos, acaba por dificultar que esse tipo de aproximação aconteça entre professores formadores e licenciandos; a História Oral foi, no entanto, um modo que encontramos para escapar desse distanciamento (muitas vezes) esperado entre aqueles que compõem ou circundam o curso.

\section{Referências}

ALVES, R. Ostra feliz não faz pérola. 1. ed. São Paulo: Planeta do Brasil, 2008.

FIORENTINI, D. A dor e a delícia de narrar e escutar histórias de professores. Prefácio. In: TEIXEIRA, I. A. C. et. al. (Org.). Viver e contar: experiências e práticas de professores de matemática. São Paulo: Livraria da Física, 2012. p. 11- 20.

GARNICA, A.V. M. Estacas em paisagens móveis: um ensaio a partir da narrativa de três professores de Matemática. In: TEIXEIRA, I. A. C. et. al. (Org.). Viver e contar: experiências e práticas de professores de matemática. São Paulo: Livraria da Física, 2012. p. 331-347.

GARNICA, A. V. M. Cartografias Contemporâneas: mapear a formação de professores de Matemática. In: GARNICA, A. V. M. (Org.). Cartografias contemporâneas: mapeando a formação de professores de Matemática no Brasil. Curitiba: Appris, 2014. p. 39-66.

LARROSA, J. Notas sobre a experiência e o saber de experiência. Tradução de João Wanderley Geraldi. Revista Brasileira de Educação, São Paulo, n. 19, p. 20-28, jan./abr. 2002.

LARROSA, J. Experiência e alteridade em Educação. Revista Reflexão e Ação, Santa Cruz do Sul, v. 19, n. 2, p. 4-27, jan./dez. 2011.

LARROSA, J. Tremores: escritos sobre experiência. 1. ed. Belo Horizonte: Autêntica, 2014.

PAULA, M. J.; AUAREK, W. A. Viver e contar. In: TEIXEIRA, I. A. C. et. al. (Org.). Viver e contar: experiências e práticas de professores de matemática. São Paulo: Livraria da Física, 2012. p. 33-40.

ROLKOUSKI, E. Histórias de vida de professores de Matemática. BOLEMA, Rio Claro, v. 21, n. 30, p. $68-88,2008$.

ROLKOUSKI, E. Vida de Professores de Matemática - (im)possibilidades de leitura. 2006. 288f. Tese (Doutorado em Educação Matemática) - Universidade Estadual Paulista, Instituto de Geociências e Ciências Exatas, Rio Claro, 2006.

SANTHIAGO, R.; MAGALHÃES, V. B. História Oral na sala de aula. 1. ed. Belo Horizonte: Autêntica, 2015.

SILVA, H. A História Oral como abordagem em espaços formativos formais de professores de Matemática. Histemat, Online, v. 2, p. 168-184, 2016. 
TEIXEIRA, I. A. C. et. al. (Org.). Viver e contar: experiências e práticas de professores de matemática. São Paulo: Livraria da Física, 2012.

TIZZO, V. S.; SILVA, H. A história oral na formação inicial de professores (de Matemática): uma abordagem possível no estudo de política educacional brasileira. Revista NUPEM, Online, v. 8, p. 27 47, 2016.

TIZZO, V. S.; FLUGGE, F. G.; SILVA, H. Práticas Possíveis com a História Oral na Formação Inicial de Professores (de Matemática). BOLEMA, Rio Claro, v. 29, n. 53, p. 887-908, 2015.

VIANNA, C. R. Sem título. In: GARNICA, A. V. M. (Org.). Cartografias contemporâneas: mapeando a formação de professores de Matemática no Brasil. Curitiba: Appris, 2014. p. 67-85.

Submetido em 02 de Outubro de 2017. Aprovado em 09 de Dezembro de 2017. 